Www.jmscr.igmpublication.org

Impact Factor 5.84

Index Copernicus Value: 71.58

ISSN (e)-2347-176x ISSN (p) 2455-0450

crossref DOI: https://dx.doi.org/10.18535/jmscr/v5i9.02

Journal Of Medical Science And Clinical Research

IGM Publication

An official Publication of IGM Publication

\title{
Evaluation of Kangaroo Mother Care in Low Birth Weight Babies
}

\author{
Authors \\ Dr Deepa.S.Phirke ${ }^{1}$, Dr Sudhakar Bantewad ${ }^{2}$ \\ ${ }^{1}$ Associate Professor, Government Medical College, Miraj, Maharashtra, India \\ ${ }^{2}$ Assistant Professor, Government Medical College, Miraj, Maharashtra, India
}

\begin{abstract}
Introduction: Kangaroo Mother Care $(K M C)$ is a simple and effective way to improve the health in low birth weight (LBW)babies in peripheral health centres with ill equipped infra-structure. It achieves a better thermal control and stabilises the vital parameters besides effectively increasing the breast feeding and improvement in the weight gain. Various studies conducted have variable results regarding the effect of KMC on babies. Hence there is a need to further evaluate it's effect.

Aims and Objectives: To evaluate the effect of KMC on low birth weight babies.

Materials and Methods-It is an prospective observational study conducted in neonatal care unit of tertiary care centre. Mothers with their LBW babies were included as per the inclusion and exclusion criteria.KMC was started in these babies after counselling of mothers. The details of gestational age, Birth weight, Weight gain were recorded. The vital parameters such as temperature, Heart rate and Respiratory rate and $\mathrm{SPO}_{2}$ was also recorded before and after $K M C$.
\end{abstract}

Results: Total 80 newborns were enrolled in this study. Out of these 40 newborns had a gestational age of 3234 weeks, the mean birth weight was $1.626 \mathrm{KG}$. The increase in the weight after KMC was seen in 40 babies out of 57 after 4 days and all babies after 8-12 days of KMC with an average weight gain of 14.53 gms. The change in temperature ranged from -2 to $+2{ }^{\circ} \mathrm{F}$ and 78 babies had increased in temperature. The change in heart rate $(H R)$ ranged from 3 to 12 beats/min. 73 babies had decreased heart rate. The range of change in respiratory rate $(R R)$ was 3 to 8 per minute. Total 75 babies had a decreased RR. The change in $S_{2} O_{2}$ was 3 to 8 and total 78 babies showed an increase in the $\mathrm{SPO}_{2}$. The mean of HR was 146.95 and 139.55, For RR 45.96 and 40.175, for temperature 97.69 and 98.50 and was 93.55 -97.48 for $\mathrm{SPO}_{2}$ before and after receiving KMC respectively.P value was $<0.0001$ in all parameters.

Discussion: Majority of babies were between 32-34 weeks of gestation and with a mean birth weight of 1.626 $\mathrm{kg}$. The chances of gain in the weight increased with increase in duration of KMC. There was significant increase in the temperature and $\mathrm{SPO}_{2}$ and decrease in HR and RR after KMC in majority of Babies.

Keywords: Kangaroo Mother Care(KMC).Low birth weight (LBW) babies, Vital parameters.

\section{Introduction}

Low birth weight (LBW) babies contribute a major role in the high neonatal mortality rate globally and especially in developing countries like India. Hence LBW babies require special care and interventions to improve their survival rate. In developing countries, due to limited advanced interventions, lack of trained staff and ill equipped infrastructure, it is difficult to achieve this task.

To overcome these problems Kangaroo mother care (KMC) was introduced in 1978 in Columbia. The term kangaroo has been taken because infant of Kangaroo is always born premature and is guided into the maternal pouch, where it remains 
warm and can have adequate feeding until maturation. It is a simple and effective modality to ensure baby's needs of warmth, stimulation and safety. It fosters the well being of the babies by promoting temperature control, ease of breast feeding, and strengthening the bond between mother and baby. This intervention helps easy transition and adaptation of a newborn to the external environment. It can be easily administered at any set up, does not require trained staff or advanced facilities and can be also be continued at home. Newborns who receive KMC soon after birth nurse more effectively at breasts, which thus increases milk production and enhances weight gain.

The major components of KMC are ${ }^{1}$

1) Skin to skin contact-The baby is placed on the mother's chest in between the breasts. This early, continuous and prolonged skin to skin contact is the basic component of KMC.

2) Exclusive Breast feeding- Mother can exclusively breast feed the baby as the skin to skin contact promotes and stimulates lactation and increases the bond between both.

Skin to skin contact initiates sensory, stimuli like touch and temperature which helps in oxytocin and prolactin release ${ }^{2}$. Oxytocin not only stimulates ejection of breast milk but also increases the temperature of the breasts and provides warmth to the baby. It also helps in relieving maternal anxiety.

3) Early discharge from hospital

KMC can be a) Continuous -where skin to skin contact between baby and mother exceeds 20 hours per day. b) IntermittentThe skin to skin contact is for shorter periods in the day. At least 70 minutes per day.

KMC procedure- Baby is placed naked over the bare chest of the mother in between the breasts in an upright position. A open gown or loose blouse is wrapped to hold the baby. Mother can sit or sleep in a propped up position so that the baby remains upright. Baby can suckle at the breasts as often as he/she can. If environmental temperature is low then baby can have extra clothing to ensure warmth.

Various studies have suggested that KMC not only ensures a proper thermal control but also influences other vital parameters and promotes weight gain, improves lactation ${ }^{3}$ and reduces the hospital stay. It also increases the sleep time and reduces cortisol levels ${ }^{4}$. The oxytocin released due to the touch stabilises targets the brainstem and stabilises the cardio-respiratory variables.KMC also reduces the heat loss and helps baby to achieve a stable thermal control. But result of few studies are contradictory to this. Hence there is a need of further research on this simple modality to assess the effect of KMC on low birth weight babies.

\section{Materials and Methods}

This study was a prospective observational study conducted in the Neonatal intensive care unit of a tertiary care hospital from January 2016 to December 2016.Total 80 babies were enrolled in the data as per the inclusion and exclusion criteria. All LBW babies who were hemodynamically stable and whose mothers gave a prior consent were included. Babies who were having any systemic disease and those born to mothers who were on drugs that could effect the neurological status of the neonate were excluded .After taking a prior consent, the mothers were counselled and trained regarding the KMC care. Details of babie's gestational age, Birth weight, Weight before starting and the end of KMC care was taken. The babies were placed naked over bare chest of mother and then wrapped by a KMC gown. KMC was given for at least $90 \mathrm{~min}$. The vital parameters such as heart rate, Respiratory rate, temperature were recorded in each baby before and after starting the $\mathrm{KMC}$ care. The $\mathrm{SPO}_{2}$ was also measured similarly by using pulseoximetry. The data was further analysed using different statistical methods. 
Results

Table no-1-Distribution of Cases according to Birth weight

\begin{tabular}{|l|c|c|}
\hline Birth weight & No. of patients & Percentage(\%) \\
\hline$<1 \mathrm{~kg}$ & 12 & 15 \\
\hline $1-1.5 \mathrm{~kg}$ & 53 & 66.25 \\
\hline $1.5-2.5 \mathrm{~kg}$ & 15 & 18.75 \\
\hline Total & 80 & 100 \\
\hline
\end{tabular}

Table no-2 Distribution of cases according to the Gestational age of newborns

\begin{tabular}{|l|c|c|}
\hline Gestational Age(Weeks) & No & Percentage \\
\hline $29-32$ & 32 & 40 \\
\hline $33-36$ & 40 & 10 \\
\hline$>37$ & 8 & 10 \\
\hline
\end{tabular}

Table no 3- Comparison of cases according to weight gain and duration of KMC.

\begin{tabular}{|l|c|c|c|c|c|}
\hline Duration & No of cases & Mean \pm SD & Decreased & Increased & No change \\
\hline $1-4$ & 56 & $-1.071 \pm 200.6$ & 9 & 40 & 7 \\
\hline $5-8$ & 19 & $54.11 \pm 37.43$ & 0 & 19 & 0 \\
\hline $9-12$ & 5 & $39.00 \pm 16.73$ & 0 & 5 & 0 \\
\hline Total & 80 & & & & \\
\hline
\end{tabular}

Table no 4-Comparison of temperature before and after KMC

\begin{tabular}{|l|c|c|c|c|c|}
\hline Range $\left({ }^{\circ} \mathrm{F}\right)$ & No of cases & Mean \pm SD & Decreased & Increased & No change \\
\hline-2 to 1.00 & 59 & $0.5102 \pm 0.2740$ & 1 & 57 & 1 \\
\hline 1.01 to 2.00 & 19 & $1.511 \pm 0.2470$ & 0 & 19 & 0 \\
\hline$>2.00$ & 2 & $2.90 \pm 0.7071$ & 0 & 2 & 0 \\
\hline Total & 80 & & 1 & 78 & 1 \\
\hline
\end{tabular}

Table no 5- Comparison of Heart rate before and after KMC

\begin{tabular}{|l|c|c|c|c|c|}
\hline Range & No of cases & Mean \pm SD & Decreased & Increased & No change \\
\hline$<3$ & 18 & $-0.055 \pm 4.759$ & 11 & 1 & 6 \\
\hline $4-12$ & 54 & $7.296 \pm 2.717$ & 54 & 0 & 0 \\
\hline$>12$ & 8 & $21.75 \pm 16.33$ & 8 & 0 & 0 \\
\hline Total & 80 & & 73 & 1 & 6 \\
\hline
\end{tabular}

Table no 6- Comparison of Respiratory rate Before and after KMC

\begin{tabular}{|l|c|c|c|c|c|}
\hline Range & No of cases & Mean \pm SD & Decreased & Increased & No change \\
\hline$<3$ & 18 & $1.056 \pm 1.955$ & 13 & 1 & 4 \\
\hline $4-8$ & 48 & $5.750 \pm 1.644$ & 48 & 0 & 0 \\
\hline$>8$ & 14 & $12.00 \pm 1.922$ & 14 & 0 & 0 \\
\hline Total & 80 & & 75 & 1 & 4 \\
\hline
\end{tabular}

Table no 7- Comparison of $\mathrm{SPO}_{2}$ before and after $\mathrm{KMC}$

\begin{tabular}{|l|c|c|c|c|c|}
\hline Range & No of cases & Mean \pm SD & Decreased & Increased & No change \\
\hline $0-3$ & 36 & $2.167 \pm 0.8783$ & 0 & 34 & 2 \\
\hline $4-6$ & 36 & $4.917 \pm 0.8062$ & 0 & 36 & 0 \\
\hline $7-8$ & 8 & $7.50 \pm 0.5345$ & 0 & 8 & 0 \\
\hline Total & 80 & & & & \\
\hline
\end{tabular}

Table no 8 - Effect of KMC on vital parameters in LBW babies

\begin{tabular}{|l|l|l|l|l|l|}
\hline & KMC & Mean & SD & t Value & P Value \\
\hline \multirow{2}{*}{ Heart rate } & Before & 146.98 & 7.311 & 8.488 & $\mathrm{P}<0.0001$ \\
\cline { 2 - 4 } & After & 139.55 & 2.824 & & \\
\hline \multirow{2}{*}{ Respiratory Rate } & Before & 45.96 & 3.584 & 0.6692 & $\mathrm{P}<0.0001$ \\
\cline { 2 - 4 } & After & 40.175 & 3.415 & & \\
\cline { 2 - 4 } & Before & 97.69 & 0.5768 & 1.116 & $\mathrm{P}<0.0001$ \\
\cline { 2 - 4 } & After & 98.50 & 0.3294 & & \\
\cline { 1 - 3 }${ }_{2}$ & Before & 93.55 & 2.104 & & $\mathrm{P}<0.0001$ \\
\cline { 2 - 4 } & After & 97.48 & 1.501 & & \\
\hline
\end{tabular}




\section{Discussion}

In developing countries like India, the conventional neonatal care is not easily available or scarce. Lack of advanced equipments, trained staff and good infrastructure limits the chances of improvement in the survival rate in newborn babies especially the LBW babies. Kangaroo mother care (KMC) is a good modality to promote the well being in the LBW babies. It is an simple approach that does not require trained staff ${ }^{5,6}$ and can be delivered even at peripheral health centres and can also be continued at home. KMC not only has benefits for the baby but is also beneficial for mothers too.

The early neonatal period is stressful for every newborn .Smooth transition to the new external environment essential for systemic and autonomic maturation is more difficult in low birth weight babies due to many complications associated in these babies like hypothermia, hypoglycaemia, Sepsis etc.KMC offers an effective care to both babies and mother ${ }^{7,8,9}$. Thus ensures and promotes a chance for sensory stimulation by increasing the bond between mother and baby. Various studies have been conducted to assess the effectiveness of KMC. Studies on effect of KMC on weight gain, thermal stability, stay in hospital and various vital parametetrs ${ }^{10}$ have been conducted and have variable results.

In this study, Total 80 LBW babies received KMC care. Majority of babies (40/80) were 32-34 weeks of gestation and birth weight was $1-1.5 \mathrm{~kg}$. (53/80). The mean birth weight was $1.626 \mathrm{~kg}$. Majority of babies, 40/56 had a weight gain after 4 days of KMC. While all babies (19 and 5) who received KMC for 5-8 days and 7-12 days respectively had significant weight gain. the average weight gain was $14.53 \mathrm{gms}$. This signifies that the chances of weight gain are more if KMC is continued for a longer duration ${ }^{11}$. A randomized controlled trial was done on 114 neonates, delivered at Jawaharlal Nehru Medical College (JNMCH) Aligarh, India which concluded better weight gain per day $(19.3 \pm 3.8 \mathrm{~g}$ vs.10.4 $\pm 4.8 \mathrm{~g}$, $\mathrm{p}<0.001)$.
We observed that only 1 baby had decrease in the temperature and 1 had no change in temperature out of 80 babies. Rest all 78 babies had a significant increase in body temperature. The mean temperature before $\mathrm{KMC}$ was $97.69^{\circ} \mathrm{F}$ and after was 98.5.The difference was statistically significant with a $\mathrm{p}$ value of $<0.0001$. . Bera et al 12 concluded in his study that mean temperature increased by about $0.4^{\circ} \mathrm{C}$ after $\mathrm{KMC}$ and was statistically significant. Temperature maintenance is minimal or absent in LBW babies due to less amount of brown fat and muscular activity and large surface area .KMC provides warmth with skin to skin contact through conduction and also prevents heat loss. Thus it protects the newborn from complications occurring secondary to hypothermia like hypoglycaemia, hypoxia, apnoea etc

We observed a mean HR of 146.98 and 139.55 beats/min before and after KMC respectively. This change was statistically significant. ( $\mathrm{P}$ value $<0.0001)$. Total 73 babies had decreased HR while 6 did not show any change and only 1 baby had increased HR. Parmar VR et al ${ }^{13}$, in their observational study found that the heart rate dropped by 3-5 beats per minute $(150 \pm 8.5$ to $147 \pm 7.50, \mathrm{p}>0.05$. Almeida $\mathrm{CM}$ et al ${ }^{14}$ noted that there was no statistically significant difference in relation to the heart rate after KMC for 30 mins. A change in a heart rate (HR) represents the balance between vagal and sympathetic regulation. KMC can initially increase the HR but later decreases HR within physiological limits. Babies cry less when placed in skin to skin contact with their mothers during KMC. It also increases duration of sleep ${ }^{15}$. These factors ensure a lower levels of cortisol in the baby. The c-afferent nerves of the mother's and infant's chest surfaces respond to touch of KMC and s stimulate oxytocin release which stabilises cardio-respiratory parameters. Some babies may have increase in HR due to upright position of baby during KMC. ${ }^{16,17}$

In this study, The mean RR before KMC was $45.96 \pm 3.584$ and $40.175 \pm 3.415$ after KMC. Total 75 babies had decrease in RR while 4 did not show any change and 1 baby had increased RR. 
Fohe et al ${ }^{18}$ and Gazzalo et al ${ }^{19}$ oserved that RR was significantly decreased during KMC while Tornhage $\mathrm{CB}$ and Fischer CJ ${ }^{20}$ observed a minimal change during $\mathrm{KMC}$.Almeida $\mathrm{CM}$ et al observed that the mean RR before KMC was 41.35 breaths per minute and 36.8 breaths per minute after $\mathrm{KMC}$, and this difference was statistically significant ( $\mathrm{P}$ value 0.000) (6). An upright position of the infant during $\mathrm{KMC}$ in which the infant is held in a ventral position at an angle of $60^{\circ}$ decreases the compression of the diaphragm. Thus helps in stabilising the RR.

$\mathrm{SPO}_{2}$ (Oxygen saturation) is defined as the fraction of oxygen-saturated haemoglobin relative to total haemoglobin (unsaturated + saturated) in the blood. We observed a mean SPO2 of 93.55 \pm 2.104 before KMC and 97.48 \pm 1.501 after KMC.78 babies had increased SPO2 while only 2 did not show any change. There was significant improvement in oxygen saturation during the KMC in study by Bera et al. Ali SM et al has shown a significant increase in $\mathrm{SpO} 2$ after $1 \mathrm{hr}$ of KMC. In the study of Almeida et al, it was observed that the median oxygen saturation was 93.8 and 97.3 before and after KMC. was statistically significant. However, a meta-analysis conducted by Mori et al ${ }^{21}$ concluded that there was a decrease in $\mathrm{SpO} 2$ of babies after KMC which was contrary to the findings in our study .

\section{Conclusion}

KMC offers an effective care to both babies and mother. It ensures and promotes a chance for sensory stimulation by increasing the bond between mother and baby. KMC not only ensures a proper thermal control but also effects the vital parameters positively to promote weight gain and improve lactation.

\section{Acknowledgement}

Dean, GMC Miraj, Nursing staff NICU at GMCH, Miraj and PVPGH, Sangli.

No funding

No conflicts declared

Approval of ethical committee taken.

\section{Bibliography}

1. Bailey S.Kangaroo mother care:A practical guide. WHO Reprod Heal Res 2003;73 (5):1-54.

2. Roos Tony and Nyrie. The Hormonal Benefits for Mothers and Babies of Kangaroo Mother Care by Tony and Nyrie Roos. Available from: http://www.articlecity.com /articles /parenting/article_2759.shtml

3. Udani RH,Hinduja ARA,NSRP,Kabra NS.Role of Kangaroo mother carein preventing Neonatal morbidity in the hospital \& community: A review article.J.Neonatol.2014;28(4):28-36.

4. Mooncey S,Giannakoulpoulas X,Glover $\mathrm{V}$,Acolet D,Modi N:The effect of mother infant skin to skin contact on plasma cortisol and $\beta$-endorphin concentrations in preterm newborns.Infant Behav Dev.1997 Oct;2014(4):553-7.

5. Thukral A,Chawla D,Agarwal R,Deorari AK,Paul VK.Kangaroo mother care-an alternative to conventional care.Indian $\mathrm{J}$ Pediatr.2008 May;75(5):497-50

6. Udani RH,Hinduja ARA,NSRP,Kabra NS.Role of Kangaroo mother carein preventing Neonatal morbidity in the hospital \& community:A review article.J. Neonatol.2014;28(4):28-36.

7. Suman Rao PN,Udani R,Nanavati RKangaroo mother care for low birth weight infants-A randomised controlled trial. Indian Pediatr,2008;45(1):17-23.

8. Nashwa M Samra,Amal El Taweel,Karin Cadwell-Effect of intermittent Kangaroo mother care on weight gain of Low birth weight neonates with delayed weight gainJ Perinat Educ.2013 Fall;22(4):194-200.

9. Sarparast L,Farhadi R,Sarparast M, Shafais-The effect of Kangaroo mother care on Neonatal outcomes in Iranian Hospitals: A review;J Pediatr Rev,2015;3(1):e 195

10. Whitney Stuard The effect of Kangaroo mother care on a newborn development 
and vital physiology,Clinics Mother Child Health Feb 2016;13:225

11. Ghavane S,Murki S,Subramaniam S, Gaddam P,Kandraju $\mathrm{H}$ and Thumalla SKangaroo mother care in Kangaroo ward for improving the growth and breast feeding outcomes when reaching term gestational age in very low birth weight infants.Acta Paediatrica 2012;101:e545-47

12. Bera A,Ghosh J,Singh AK,Hazra bA,Som T,Munian D.Effect of kangaroo mother care on vital physiological parameters of low birth weight newborn.Indian $\mathrm{J}$ Community Med.2014 Oct.39(4):28-36

13. Parmar VR, Kumar A, Kaur R, Parmar S, Kaur D, Basu S, et al. Experience with Kangaroo mother care in a neonatal intensive care unit (NICU) in Chandigarh, India. Indian J Pediatr. 2009;76(1):25-8

14. Almeida C,Almeida A,Forti E.Effects of Kangaroo mother care on vital signs of low weight preterm newborns.Rev Bras fisioter:2009;11(1):1-5

15. Ludington-Hoe SM, Johnson MW, Morgan K, Lewis T, Gutman J, Wilson PD, et al. Neurophysiologic Assessment of Neonatal Sleep Organization: Preliminary Results of a Randomized, Controlled Trial of Skin Contact With Preterm Infants. Pediatrics. 2006 May 1;117(5):e909-23

16. Malliani A, Montano N, Pagani M. Physiological Background of Heart Rate Variability. Card Electrophysiol Rev. 1997;1(3):343-6

17. Thoresen M, Cowan F, Walløe L, Borst C, Wieling W, Brederode JFM van, et al. Cardiovascular responses to tilting in healthy newborn babies. Early Hum Dev. 1991 Oct ; 26(3):213-22

18. Föhe K, Kropf S, Avenarius S. Skin-toSkin Contact Improves Gas Exchange in Premature Infants. J Perinatol. 2000 May $1 ; 20(5): 311-5$
19. Gazzolo D, Masetti P, Meli M. Kangaroo care improves post-extubation cardiorespiratory parameters in infants after open heart surgery. Acta Paediatr. 2000 Jun;89(6):728

20. Törnhage C-J, Stuge E, Lindberg T, Serenius F. First week kangaroo care in sick very preterm infants. Acta Paediatr. 2007 Jan 2;88(12):1402-4

21. Mori R,Khanna R,Pledge D,Nakayama T,Meta analysis of physiological effects of skin to skin contact for newborn and mothers.Pediatr Int.2010 Apr;52(2) 16170 . 